\title{
Mapeamento da Oferta de Capacitação nas Escolas de Governo no Brasil: gestão da informação para fortalecimento da gestão pública ${ }^{1}$
}

Elisabete Ferrarezi e João Alberto Tomacheski

\section{Introdução}

O projeto Mapeamento da Oferta de Capacitação nas Escolas de Governo foi resultado de um trabalho conjunto entre as instituições integrantes da Rede Nacional de Escolas de Governo e a Escola Nacional de Administração Pública (ENAP).

A rede tem por objetivo aumentar a eficácia das instituições que trabalham com formação e aperfeiçoamento profissional dos servidores públicos dos três níveis de governo, por meio do intercâmbio de conhecimentos e de práticas, incentivando trabalhos em parceria. Criada por iniciativa da ENAP em 2003, a rede congrega atualmente 170 escolas de governo e instituições similares (http:/ /www2.enap.gov.br/rede_escolas/).

O projeto de mapeamento, iniciado em 2008, tinha por objetivo coletar dados da oferta existente de eventos de formação e capacitação nas escolas de governo que integram a rede. $\mathrm{O}$ projeto teve como produto um instrumento de 
informações gerenciais informatizado: o Sistema Mapa ${ }^{1}$. Esse produto de um processo de construção coletiva da Rede de Escolas reuniu informações sobre a oferta de capacitação por meio da agregação e disponibilização dos cursos oferecidos, ementas, carga horária e número de beneficiários, além de informações sobre a infraestrutura disponível em cada instituição.

O pressuposto era que, com a reunião das informações sobre oferta de cursos numa única base, os esforços de capacitação poderiam ser potencializados com informações disponíveis aos servidores, dirigentes governamentais e organismos internacionais que investem em processos de capacitação. O compar-tilhamento dessas informações, por meio do sistema, possibilitaria não só a comparação de conteúdos e sua classificação em áreas de conhecimento, mas também a identificação de tendências de capacitação, temas emergentes, lacunas e potenciais para o desenvolvimento de determinadas competências.

Com a participação das instituições da Rede de Escolas na atualização constante das informações do Sistema Mapa, espera-se que a iniciativa traga os seguintes resultados: fortalecimento da Rede, com aumento de ações integradas das instituições participantes; informações gerenciais permanentemente atualizadas sobre a oferta de cursos, fornecendo aos gestores e dirigentes os meios para planejar e realizar processos de capacitação, utilizando de forma eficiente a oferta existente nas escolas de governo; melhoria na coordenação de atividades de capacitação e incentivo à complementaridade, com redução de duplicidade e ampliação da comunicação entre as escolas.

Este artigo apresenta um breve histórico do projeto de implantação do Sistema
Mapa e os desafios futuros para sua consolidação. Apresenta algumas informações extraídas do sistema e identifica as possibilidades que se abrem para o gerenciamento das informações estratégicas visando à tomada de decisões e à otimização dos recursos disponíveis para a capacitação.

\section{A importância do Mapeamento da Oferta de Capacitação nas Escolas de Governo}

A maioria dos servidores públicos brasileiros está ligada aos governos municipais ou estaduais. E a maioria dos servidores públicos federais está lotada fora do centro administrativo da capital federal, em Brasília. Segundo estimativas feitas pelo Instituto de Pesquisa Econômica Aplicada (Ipea), tendo como base o ano de 2006, havia naquele período 10.168.680 servidores públicos nas três esferas de governo. A região centro-oeste, onde se localiza a capital federal, concentraria somente 9,08\% dos 922.896 servidores públicos estimados no estudo.

Como a maioria dos servidores públicos encontra-se fora de Brasilia, qualquer plano de capacitação em larga escala deve considerar essa situação geopolítica e ter informações qualificadas para o planejamento e sobre as alternativas de formação.

Além disso, considerando os processos de democratização e descentralização, a implementação das políticas públicas vem exigindo diálogo, coordenação e cooperação intra e intergovernamental das três esferas federativas e, cada vez mais, dada a complexidade do ambiente em que ocorre a execução, demanda pessoal com competências desenvolvidas para a gestão, controle e monitoramento das ações em ambientes complexos. 
Tabela 1 - Estimativa de servidores públicos no Brasil em 2006, distribuídos segundo regiões do País

\begin{tabular}{lll}
\hline Regiões & N. de servidores & \% do total \\
\hline Sudeste & 4.179 .463 & 41,1 \\
Nordeste & 2.691 .932 & 26,47 \\
Sul & 1.490 .751 & 14,66 \\
Centro-Oeste & 922.896 & 9,08 \\
Norte & 883.638 & 8,69 \\
\hline Total & 10.168 .680 & 100 \\
\hline
\end{tabular}

Fonte: Instituto de Pesquisa Econômica Aplicada (BRASIL, 2009, p. 7).

Em relação ao Poder Executivo federal, informações de junho de 2010, do Ministério do Planejamento, apontam para a existência de 1.095 .685 servidores ativos, sendo que, desses, $570.607(52,07 \%)$ seriam servidores civis. Somente $11,6 \%$ dos servidores civis estariam lotados em Brasília (BRASIL, 2010), o que revela uma força de trabalho no setor público, mesmo em nível federal, bastante descentralizada.

Considerando-se as estimativas do Ipea para 2006 sobre o número de servidores públicos nas três esferas de governo (10,1 milhões) e o número de servidores do executivo federal existentes em 2008 (1,1 milhão, segundo o MP), pode-se inferir que menos de $11 \%$ dos 10 milhões de servidores públicos são ligados ao governo federal ${ }^{1}$. Os $89 \%$ dos demais servidores públicos estariam nos municípios (49\%) e nos estados (40\%).

Portanto, mesmo que sejam consideradas somente as necessidades de capacitação dos servidores federais, percebe-se a importância de uma ação colaborativa entre os órgãos de gestão de pessoas e centros federais, estaduais e municipais de formação.

A capacitação dos servidores públicos é desenvolvida no Poder Executivo
- governos federal, estadual e municipal , bem como no Legislativo e Judiciário, por órgãos de diversas naturezas.

Cabe a esse conjunto de instituições a responsabilidade de estimular, de forma permanente, o desenvolvimento de competências profissionais e a disseminação do conhecimento em gestão pública.

Mas esse universo de instituições, ainda não totalmente conhecido, é bastante heterogêneo em relação a capacidades, meios, recursos e expertise, embora compartilhe problemas e desafios semelhantes.

O desenvolvimento de competências, habilidades e atitudes de servidores públicos por meio de capacitação envolve não apenas o conhecimento explícito, mas, também, o conhecimento tácito oriundo da resolução de problemas práticos, além de metodologias teórico-aplicadas de ensino-aprendizagem, guardando aproximação com a realidade em que os servidores atuam. Essa "especificidade" de escola de governo exige o desenvolvimento de instrumentos pedagógicos mais adequados ao ensino aplicado e profissional, que vêm muito lentamente sendo produzidos para o ensino da administração pública no Brasil, e sobre os quais temos reduzida experiência. Esses são 
temas específicos da agenda de escolas de governo, que terão de ser tratados e desenvolvidos.

No governo federal, o processo de capacitação permanente deve ser orientado pela busca de adequação entre as competências do quadro de servidores e as habilidades exigidas em cada área de atuação do Estado, de acordo com o previsto na Política Nacional de Desenvolvimento de Pessoal - (PNDP), criada pelo Decreto $n^{\circ}$ 5.707, de 23/02/06 (Brasil, 2006). Esse decreto determina que os dirigentes públicos busquem o desenvolvimento permanente de competências do servidor público e dos órgãos governamentais com vistas à melhoria da eficiência, eficácia e qualidade dos serviços públicos prestados ao cidadão. Como existem servidores federais nos estados, o conhecimento da existência de capacidade instalada para determinados cursos, nesses locais, pode proporcionar a descentralização de capacitação e formação desses funcionários.

Mesmo existindo necessidades diferentes de capacitação dos servidores, tendo em vista o papel de cada ente federado nas políticas públicas, existe uma série de desafios e problemas que são comuns, e para os quais já existem desenhos instrucionais testados e avaliados. Essa informação pode ser tratada a fim de gerar conhecimento com potencial para adaptação e disseminação para outras esferas de governo. Como resultado desse processo, haveria informações e indicadores que auxiliariam a tomada de decisões para o planejamento, permitindo, assim, um melhor aproveitamento da oferta de cursos de cada escola e um consequente aumento no número de capacitações realizadas.

Entre as iniciativas que buscam criar uma base comum de ação entre os centros formadores de servidores, destaca-se a Rede Nacional de Escolas de Governo. A iniciativa introduzida em 2003 teve, nos últimos dois anos, forte adesão das escolas de governo. Em dezembro de 2008, a rede era composta por 102 instituições e atualmente (outubro de 2010) é composta por 170 entidades.

Das 170 instituições integrantes da rede, 42 são escolas federais, 88 estaduais e 40 municipais. São escolas de governo (que possuem regimes jurídicos, orçamento e infraestrutura diferenciados), universidades corporativas e mesmo unidades de recursos humanos vinculadas a secretarias de administração e planejamento de governos estaduais e municipais e também aos poderes Legislativos e Judiciários. Trata-se assim de um conjunto significativo de entidades, que provavelmente abriga a maioria das escolas de governo do Brasil.

Tabela 2- Distribuição regional das instituições integrantes da Rede Nacional de Escolas de Governo

\begin{tabular}{lll}
\hline Região & N. & \% \\
\hline Sudeste & 51 & 30 \\
Centro-Oeste & 40 & 23,53 \\
Nordeste & 38 & 22,35 \\
Sul & 22 & 12,94 \\
Norte & 19 & 11,18 \\
\hline Total & $\mathbf{1 7 0}$ & 100 \\
\hline
\end{tabular}

Fonte: Pesquisa ENAP (2010) 
No entanto, não existiam informações sistematizadas para o país sobre a oferta de capacitação, o que dificultava o desenho de estratégias e programas de desenvolvimento de pessoal que articulassem os níveis de governo, para aproveitar a potencialidade de cada escola e da região. Visando preencher essa lacuna de informação, foi concebido o projeto de Mapeamento da Oferta das Capacitações nas Escolas de Governo, que resultou no Sistema Mapa ${ }^{1}$.

\section{Características e fases do Mapeamento da Oferta das Capacitações nas Escolas de Governo}

O projeto de Mapeamento da Oferta das Capacitações nas Escolas de Governo buscou inicialmente ampliar a comunicação entre as escolas de governo e o intercâmbio nas atividades de capacitação, além do fortalecimento da própria Rede Nacional de Escolas de Governo.

Esse projeto resultou no Sistema Mapa, que permite armazenar e processar dados sobre a oferta de capacitações de instituições integrantes da rede de escolas, contendo informações sobre a oferta de cursos, capacitações realizadas, infraestrutura física etc. O Sistema Mapa foi concebido de forma que essas informações possam ser constantemente atualizadas e compartilhadas entre as instituições parceiras, além de produzir informações gerenciais aos gestores públicos dos três entes federados.

O projeto de implantação foi concebido em três fases:

- Coleta das informações sobre a oferta de capacitações nas escolas de governo por meio do preenchimento do cadastro pelas instituições no sistema preliminar;
- Organização das informações sobre a oferta de cursos por meio da criação de um vocabulário controlado, que produziu equivalência semântica do conteúdo dos cursos, possibilitando uma visualização desses cursos em um mapa organizado segundo grandes áreas do conhecimento;

- Organização dos produtos e informações das duas fases anteriores em um sistema com interface web: o Sistema Mapa.

A equipe responsável pelo projeto desde o início considerava que o enfoque participativo era fator crítico para o sucesso de uma iniciativa desenvolvida em uma rede, organizada a partir de relações não hierárquicas.

Redes se referem a relações, ou possibilidades em latência. Sua configuração é previsível apenas quando desenha relações entre os elementos, o que faz dela uma emergência e não uma entidade. Trata-se de movimentos de relacionamentos que criam várias ordens e possibilidades, dependendo da interação dos participantes. Os relacionamentos seriam caminhos por onde trafegam as oportunidades, acionando produtivamente o mundo do possível. As redes significariam um incremento das probabilidades de realização já que oferecem possibilidades de relacionamentos (Martinho, 2003, p. 29). Em outras palavras, o termo rede designaria um movimento pouco institucionalizado, reunindo indivíduos ou grupos numa associação cujos limites são variáveis e sujeitos a reinterpretações e conflitos.

Considerando-se as características constitutivas de uma rede e o fato de o mapeamento ter o potencial de incrementar intercâmbios, a ENAP decidiu por uma estratégia no projeto que tinha o diálogo político e o compartilhamento das informações como princípios. 
Assim, foi elaborado um plano de divulgação e mobilização dos integrantes da rede, já que não existia nenhuma obrigatoriedade para participação no projeto. A adesão das instituições constituía um ponto crítico e era fundamental para o sucesso da iniciativa, pois elas precisariam manter as informações coletadas constantemente atualizadas.

Ao contrário dos ativos comuns, a informação pode ser compartilhada infinitamente e usada simultaneamente por muitas pessoas, sem que seja consumida nesse processo (BEAL, 2004, p. 22). Essa característica permite que a informação seja utilizada internamente, buscando influenciar o comportamento dos indivíduos para que suas ações sejam condizentes com os objetivos e a missão das organizações e dos governos, e, externamente, visando à publicização de dados e à prestação de contas para cidadãos e parceiros.

Esse processo exige que os participantes organizem suas informações operacionais e gerenciais para alimentar $\mathrm{o}$ sistema Mapa e se disponham ao processo colaborativo para sua permanente atualização, evitando o problema do "carona", presente em qualquer ação coletiva (Olson, 1971).

O valor da informação aumenta com seu uso. Quanto maior o número de pessoas que a utiliza, maior o benefício econômico que dela pode ser extraído (Moody E Walsh apud BeAL, 2004, p. 24). Mas a informação adquire valor quando está adaptada às necessidades dos usuários, quando se sabe onde encontrá-la e como utilizá-la.

Algum grau de imprecisão sempre existirá, mas tendo em vista as propriedades da informação de qualidade, que adicionam valor (validade, relevância, precisão, confiabilidade), torna-se ainda mais importante a estratégia de participação e envolvimento dos integrantes do projeto para o tratamento da informação.

Tendo em conta esses aspectos, desde o início do projeto a equipe responsável pela iniciativa procurou engajar as organizações, buscando um modelo compartilhado de decisão.

Além da inserção das informações sobre a oferta de cursos e das informações cadastrais, as escolas participaram da definição dos campos do formulário de coleta de dados e introduziram e homologaram as classificações propostas pelo vocabulário controlado. Para isso, foram feitos dois encontros presenciais em 2008. Houve troca de sugestões utilizando um fórum on-line, troca de e-mails e divulgação de informativos na página da rede. Nesse processo, por sugestão das entidades da rede, foi inserido também um módulo de cadastro de colaboradores (professores) e participantes (alunos).

Para compartilhar todas as informações coletadas inicialmente foi utilizada a ferramenta de ensino a distância Moodle ${ }^{2}$ que, devidamente adaptada, transformouse na versão preliminar do Sistema Mapa. Cada instituição recebeu uma senha de usuário e acessou o sistema, inserindo dados. As informações coletadas, desde julho de 2008, ficaram disponíveis para as instituições da rede. Nesse repositório virtual, encontravam-se informações sobre 3.279 cursos de capacitação, inseridas por 63 das cerca de 90 organizações que compunham a rede na época da coleta.

A primeira fase de coleta de dados foi satisfatória, com adesão de quase $70 \%$ das entidades. Entretanto, como nenhum dos campos dos formulários era obrigatório, muitas escolas deixaram de inserir informações básicas, o que trouxe dificuldades para a análise das respostas ${ }^{3}$. 
Nessa primeira fase, as 63 instituições que participaram da coleta de dados indicaram 545.674 pessoas capacitadas em 2007, sendo $70 \%$ delas na modalidade presencial. Esse número de capacitações produzidas pelas 63 organizações é um indicador da importância dessas escolas. Pode-se inferir que o número de capacitações produzido pelo conjunto de escolas que participa da rede não seja inferior a um milhão de capacitações anuais.

\section{A construção do vocabulário controlado}

A construção do vocabulário controlado surgiu da constatação de que um sistema de busca textual não seria suficiente para atender às necessidades dos usuários do Sistema Mapa. Os sistemas de informação são criados para fins gerenciais, o que implica armazenar e organizar as informações de modo que possam ser encontradas quando delas se necessita. Como esses sistemas abrigam quantidades significativas de informações (que só tendem a crescer), a falta de organização provoca, inevitavelmente, perda de informação. Cursos com conteúdos idênticos podem ter denominações diversas e viceversa. Assim, foi necessário estabelecer critérios para organizar a oferta de cursos de capacitação dentro de um mapa que apresenta essas informações segundo grandes áreas de conhecimento.

Vocabulários controlados são instrumentos utilizados para organizar e filtrar informação. Para cumprir simultaneamente as funções de instrumento organizador e de filtragem, um vocabulário controlado é constituído de um conjunto finito e controlado de termos: os descritores. A organização de um vocabulário controlado implica a escolha de um único descritor para denominar alguma coisa e também a identificação das diferentes denominações pelas quais esse descritor pode ser identificado. Também implica a organização dessas diferentes denominações em rede para que apontem, invariavelmente, para o descritor, independentemente das variantes terminológicas: as relações de sinonímia. Além das relações de sinonímia, um vocabulário controlado estabelece redes hierárquicas entre os descritores, de modo a possibilitar recuperação de informação em diferentes níveis de agregação (Kobashi, 2008).

Outra característica importante do vocabulário controlado é que ele é construído com a participação de especialistas sobre o tema, mas não se constitui tarefa restrita a esses. É atividade coletiva, que requer a participação dos gestores e dos usuários do sistema de informação. Ao mesmo tempo, não é uma linguagem acabada, pois deve ser objeto de atualização periódica, de modo a refletir a dinâmica das atividades a que se propõe nomear e organizar.

As instituições da rede participaram da elaboração do vocabulário controlado, produto realizado na segunda fase do projeto. No VI Encontro da Rede Nacional de Escolas de Governo, ocorrido em Brasília, em dezembro de 2008, foi apresentada uma proposta de classificação dos cursos com cinco níveis ${ }^{4}$. A classificação utilizava como ponto de partida, os critérios de classificação de cursos elaborados pela Coordenação de Aperfeiçoamento de Pessoal de Nível Superior (Capes). Partindo desta classificação, que se tornou o nível 1 do vocabulário controlado, foram criados mais 4 níveis, hierarquicamente subordinados, tendo como nível 1 as classificações da Capes. 
Tabela 3 - Vocabulário controlado da Rede de Escolas de Governo: relação de descritores

\begin{tabular}{ll}
\hline Níveis & N. de descritores \\
\hline Nível 1 & 46 \\
Nível 2 & 378 \\
Nível 3 & 301 \\
Nível 4 & 164 \\
Nível 5 & 60 \\
\hline Total & 949 \\
\hline
\end{tabular}

Fonte: Pesquisa ENAP (2010)

A classificação proposta foi debatida e aceita pelas instituições e, em um segundo momento, cada instituição teve que avaliar se os seus cursos estavam corretamente enquadrados nas classificações propostas pela especialista no assunto. Ao final desse processo de consulta às organizações, obteve-se o primeiro vocabulário controlado da Rede de Escolas, contendo 949 descritores, divididos em cinco níveis hierárquicos:

\section{O Sistema Mapa}

O repositório construído na primeira fase do projeto continha apenas dois módulos: o cadastro com dados das instituições e o cadastro com informações de cursos. Era possível fazer buscas textuais em todos os campos existentes nos módulos, mas a informação era estática. Tratava-se de uma lista de cursos, sem possibilidade de busca avançada, aplicação de filtros ou geração de relatórios gerenciais.

Com a migração dessas informações, coletadas na primeira fase, para o Sistema Mapa, teve-se um salto qualitativo na visualização das informações, que estão consolidadas num único módulo e, ao mesmo tempo, podem ser visualizadas em diferentes níveis de classificação: segundo o tipo de instituição, áreas temáticas (vocabulário controlado), tipo de curso etc.

O Sistema Mapa possui os seguintes módulos:

Módulo de cadastro de

\section{instituição:}

- Nome e dados gerais da instituição;

- Missão ou objetivos;

- Endereço, telefone, e-mail e outras informações de contato;

- Tipo de instituição (escola de governo, universidade, $\mathrm{ONG}$ etc);

- Personalidade jurídica;

- Poder ao qual pertence (Executivo, Legislativo, Judiciário, Ministério Público);

- Informações sobre o corpo dirigente;

- Número de servidores pertencentes ao quadro próprio da instituição;

- Infraestrutura de capacitação (salas de aula, laboratórios, alojamentos etc);

- Infraestrutura de informática (computadores e conexão de internet);

- Informações sobre a biblioteca e publicações;

- Informações sobre o corpo docente, público-alvo e turnos nos quais ocorrem as atividades de capacitação; 
- Informações detalhadas sobre as capacitações realizadas.

\section{Módulo de cadastro de oferta de cursos e eventos:}

- Nome do curso ou evento;

- Tipo do curso ou evento (curso de formação, especialização, oficina etc);

- Áreas temáticas (classificação);

- Modalidade (presencial, mista, a distância);

- Público-alvo;

- Outras informações do público-alvo;

- Turno em que é ministrado;

- Ementa do curso;

- Programa do curso;

- Objetivos de aprendizagem;

- Carga horária.

\section{Módulo de colaboradores e parti- cipantes:}

- Dados cadastrais básicos dos colaboradores e participantes;

- Histórico dos cursos realizados (em todas as escolas da rede).

\section{Pesquisa avançada:}

- Utilizando o vocabulário controlado;

- Por estados ou regiões;

- Pela modalidade do curso;

- Pelo tipo de instituição.

Em novembro de 2009 o Sistema Mapa foi disponibilizado para as instituições da rede e, desde fevereiro de 2010, os dirigentes públicos dos três níveis de governo também podem consultá-lo. Entre março e julho de 2010 foram feitas várias oficinas de capacitação. Atualmente, o sistema está em processo de aperfeiçoamento, tendo em vista as sugestões feitas pelos usuários e pela equipe que o gerencia.

$\mathrm{O}$ sistema permite a inserção de informações com diferentes níveis de detalhamento. As capacitações realizadas, por exemplo, podem ser detalhadas até o nível de identificação dos participantes do referido evento ${ }^{1}$. Assim, a instituição pode identificar o participante, inserindo suas notas e frequências. O módulo de participantes possibilita que a instituição possa usá-lo como forma de registro das suas atividades de capacitação, inclusive habilitando o acesso para o participante aos registros de suas capacitações e permitindo que ele atualize suas informações cadastrais.

O módulo de colaboradores, por sua vez, possibilita que cada escola identifique quais professores foram responsáveis por determinado curso. Como se trata de cadastro único, essas informações, caso inseridas pelas escolas, poderão formar um banco de colaboradores compartilhado entre as instituições da rede, com o histórico de todas as capacitações realizadas por determinado colaborador. Tal como no módulo de participantes, o cadastro de colaboradores permite que seu públicoalvo acesse e atualize suas informações cadastrais. Ou seja, o aluno ou o professor poderá acessar e visualizar as informações armazenadas sobre sua participação em cursos de capacitação realizados pelas entidades que compõem a Rede de Escolas.

Essa identificação é feita por meio de um cadastro único, compartilhado entre as instituições que utilizam o Sistema Mapa. Visando evitar duplicidade de registros, foi criado um identificador único, utilizando-se o Cadastro de Pessoa Física $(\mathrm{CPF})^{2}$. Com a adoção desse registro único, abre-se a possibilidade de construção de um repositório com as informações de capacitação de todos os servidores que participam dos cursos promovidos pela Rede de Escolas.

A criação do registro único abre outras possibilidades de utilização do Sistema Mapa como, por exemplo, servir como registro do histórico de capacitações 
do servidor público. Durante sua vida funcional, um servidor passa por inúmeros processos de capacitação. Atualmente, a inserção dos registros sobre as capacitações realizadas pelos servidores públicos federais depende da atitude de cada um. Isso acontece em uma realidade na qual os avanços da informática poderiam automatizar esses processos, com custos baixos e gerando informações gerenciais de grande relevância para a política de gestão de pessoas e planos de capacitação. Tais informações existem, mas estão dispersas entre os diversos órgãos da administração federal ou nos centros formadores. Assim, o Sistema Mapa criou as facilidades técnicas para que esses registros possam ser disponibilizados nunca única base de dados, o que facilita o acesso às informações.

Sistema Mapa: alguns indicadores ${ }^{3}$

Em outubro de 2010, o Sistema Mapa conta com 3.707 cursos cadastrados por 81 das 170 instituições que compõem a Rede de Escolas. Observa-se grande concentração de cursos em duas regiões. Quase 70\% da oferta total de cursos está nas regiões Sudeste (40,8\%) e Centro-Oeste (28,8\%). A Região Nordeste possui 13,1\%, enquanto a Região Sul e a Norte, $11,7 \%$ e $5,7 \%$, respectivamente.
Em relação aos 3.367 cursos presenciais oferecidos pelas escolas (90,8\% do total), observa-se, igualmente, concentração da oferta na Região Sudeste e Centro-Oeste, com respectivamente 40,1\% e 23,7\%. Do total de cursos presenciais, 12,2\% está no Nordeste, 9,1\% no Sul e $5,7 \%$ no Norte (tabela 4 ).

Nota-se ainda a presença tímida de cursos a distância. Eles representam apenas $7,6 \%$ do total de cursos ofertados, com forte concentração no Centro-Oeste (4\%) e Sul $(2,5 \%)$. Caso persista a baixa incidência dessa tecnologia nas regiões mais carentes de recursos e de difícil acesso, os gestores terão de incluir em seus planos estratégias de fomento para essa modalidade (tabela 4).

Do ponto de vista das grandes áreas de conhecimento (nível 1 do vocabulário controlado), os 3.707 cursos estão classificados em 43 áreas temáticas. Dessas, existe grande concentração em 11, em que estão 80\% dos cursos: Administração, Informática, Saúde Coletiva, Direito, Medicina, Segurança, Linguística e Letras, Serviço Social, Educação, Ciências Biológicas e Economia. Dentre essas, quatro concentram $60 \%$ de todos os cursos: Administração (41,95\%), Informática (8,08\%), Saúde Coletiva $(6,07 \%)$ e Direito $(4,41 \%)$.

Tabela 4 - Sistema Mapa: cursos cadastrados no Mapa, segundo modalidade de ensino e regiões do país

\begin{tabular}{lcccccccc}
\hline $\begin{array}{l}\text { Regiões do } \\
\text { país }\end{array}$ & $\begin{array}{c}\text { Cursos } \\
\text { Presenciais }\end{array}$ & $\begin{array}{c}\text { Cursos a } \\
\text { Distância } \\
\text { (EAD) }\end{array}$ & \% & $\begin{array}{c}\text { Cursos } \\
\text { Mistos }\end{array}$ & \% & Total & \% \\
\hline Norte & 211 & 5.7 & 0 & 0.0 & 0 & 0.0 & $\mathbf{2 1 1}$ & 5,7 \\
Sul & 336 & 9.1 & 93 & 2.5 & 3 & 0.1 & $\mathbf{4 3 2}$ & 11,7 \\
Nordeste & 454 & 12.2 & 21 & 0.6 & 12 & 0.3 & $\mathbf{4 8 7}$ & 13,1 \\
Centro-Oeste & 881 & 23.7 & 149 & 4.0 & 36 & 1.0 & $\mathbf{1 0 6 6}$ & 28,8 \\
Sudeste & 1485 & 40.1 & 18 & 0.5 & 8 & 0.2 & $\mathbf{1 5 1 1}$ & 40,8 \\
\hline Totais & $\mathbf{3 3 6 7}$ & 90.8 & $\mathbf{2 8 1}$ & 7.6 & $\mathbf{5 9}$ & 1.6 & $\mathbf{3 7 0 7}$ & 100,0 \\
\hline
\end{tabular}

Fonte: Pesquisa ENAP (2010) 
Tabela 5 - Sistema Mapa: cursos classificados segundo áreas temáticas de nível 1 (*)

\begin{tabular}{|c|c|c|c|}
\hline Descritores de nível 1 & N. curso & $\%$ Total & $\%$ acumulado \\
\hline Administração & 1589 & 41.95 & 41.95 \\
\hline Informática & 306 & 8.08 & 50.03 \\
\hline Saúde Coletiva & 230 & 6.07 & 56.10 \\
\hline Direito & 167 & 4.41 & 60.51 \\
\hline Medicina & 147 & 3.88 & 64.39 \\
\hline Segurança & 141 & 3.72 & 68.11 \\
\hline Linguística e Letras & 138 & 3.64 & 71.75 \\
\hline Serviço Social & 93 & 2.46 & 74.21 \\
\hline Educação & 91 & 2.40 & 76.61 \\
\hline Ciências Biológicas & 74 & 1.95 & 78.56 \\
\hline Economia & 68 & 1.80 & 80.36 \\
\hline Ciência Política & 63 & 1.66 & 82.02 \\
\hline Farmacologia & 53 & 1.40 & 83.42 \\
\hline Enfermagem & 52 & 1.37 & 84.79 \\
\hline Geociências & 47 & 1.24 & 86.03 \\
\hline Psicologia & 43 & 1.14 & 87.17 \\
\hline Nutrição & 36 & 0.95 & 88.12 \\
\hline Ciência da Informação & 31 & 0.82 & 88.94 \\
\hline Ética & 30 & 0.79 & 89.73 \\
\hline Fisioterapia & 29 & 0.77 & 90.50 \\
\hline Terapia Ocupacional & 22 & 0.58 & 91.08 \\
\hline Probabilidade e Estatística & 22 & 0.58 & 91.66 \\
\hline Fonoaudiologia & 20 & 0.53 & 92.19 \\
\hline Esporte e Lazer & 20 & 0.53 & 92.71 \\
\hline Planejamento Urbano e Regional & 18 & 0.48 & 93.19 \\
\hline Odontologia & 18 & 0.48 & 93.66 \\
\hline Meio Ambiente & 18 & 0.48 & 94.14 \\
\hline Medicina Veterinária & 14 & 0.37 & 94.51 \\
\hline Engenharia & 12 & 0.32 & 94.83 \\
\hline Cultura & 11 & 0.29 & 95.12 \\
\hline Metodologia da Pesquisa & 10 & 0.26 & 95.38 \\
\hline Física & 9 & 0.24 & 95.62 \\
\hline Educação Física & 6 & 0.16 & 95.78 \\
\hline História & 5 & 0.13 & 95.91 \\
\hline Geografia & 4 & 0.11 & 96.01 \\
\hline Ciências Agrárias & 4 & 0.11 & 96.12 \\
\hline Sociologia & 3 & 0.08 & 96.20 \\
\hline Demografia & 3 & 0.08 & 96.28 \\
\hline Turismo & 2 & 0.05 & 96.33 \\
\hline Matemática & 2 & 0.05 & 96.38 \\
\hline Química & 1 & 0.03 & 96.41 \\
\hline Fotografia & 1 & 0.03 & 96.44 \\
\hline Arquitetura & 1 & 0.03 & 96.46 \\
\hline Sem Classificação & 134 & 3.54 & 100.00 \\
\hline Total & 3788 & 100.00 & \\
\hline
\end{tabular}

Fonte: Pesquisa ENAP (2010)

(*) Um curso pode estar cadastrado em mais de uma área temática. Dessa forma, esse número não corresponde ao número de cursos cadastrados. 
As informações do Sistema Mapa possuem potencial para planejamento e monitoramento das atividades de formação e capacitação. Mas a incorporação do sistema no dia a dia das instituições ainda é um desafio. Como há informações incompletas, não é possível extrair cruzamentos com precisão.

Mesmo com essa lacuna de informação, é possível perceber distorções que devem ser acompanhadas nas próximas análises, como a baixa incidência de educação a distância no Nordeste ou a sua inexistência na região Norte (tabela 4). Se cruzarmos a distribuição regional dos servidores no território nacional (tabela 1) com a oferta de capacitação (tabela 4), de imediato se nota que a região Nordeste concentra $26,47 \%$ dos servidores, mas tem somente $13,1 \%$ da oferta de capacitação, ao passo que a região Centro-Oeste disponibiliza $28,8 \%$ da oferta de capacitação, mas possui somente 9,08\% dos servidores.

Mesmo sendo um sistema novo, ainda em consolidação e com lacunas de preenchimento, os dados parciais apresentados neste texto revelam que há uma desigualdade no acesso à formação entre as regiões brasileiras e que ainda há muito que se pesquisar acerca das características das escolas e de como desenvolvem seu trabalho.

\section{Considerações finais}

Por fim, apontamos alguns pontos críticos do projeto que merecem ser destacados.

A adesão das instituições ao projeto de mapeamento nas primeiras fases de implantação foi bastante satisfatória. Esta foi resultado da aceitação, compreensão e construção coletiva do projeto inicial por parte das instituições que compunham a rede, assim como de um trabalho de mobilização e comunicação permanente com os parceiros. Estratégia a qual deverá continuar para que haja incentivos à atualização das informaçõesrelativas aos anos-base 2008, 2009 e 2010.

Essa demanda constitui desafio para muitas escolas, havendo, ainda, grande contingente que não inseriu nenhuma informação no sistema. Um levantamento feito em julho de 2010, junto ao último grupo, com 43 das então 73 entidades que não haviam inserido nenhuma informação no Sistema Mapa, identificou causas que contribuem para essa não participação.

Em muitos casos, o dirigente da instituição, que recebe a primeira senha do sistema, não designa ninguém para alimentá-lo. Isso ocorre porque ele desconhece o sistema ou então por não existirem pessoas disponíveis para operá-lo. Ainda contribuem as mudanças frequentes que ocorrem nas direções das escolas.

Outras razões apontadas pelos usuários locais para a não participação: desconhecimento de como acessar o Mapa ou utilizar suas funcionalidades; falta de tempo; problemas estruturais da organização, como equipes reduzidas ou instituições em processo de estruturação ou reestruturação.

Com base nesse diagnóstico, foram propostas algumas ações visando aumentar a participação: estabelecer regras claras de participação na rede (papel da rede e das instituições, compromisso esperado, regras, objetivos etc); realizar, de forma contínua, pesquisas, informes, reuniões, encontros e seminários sobre temas de interesse da rede; realizar sucessivas oficinas de capacitação sobre as funcionalidades do Sistema Mapa; utilizar ferramentas tecnológicas para que o Mapa possa 
facilitar e estimular a interação na rede (comunidades virtuais, redes sociais etc).

Além disso, a definição de quem poderá ou não ter acesso ao sistema, com a inclusão de outras instituições, como universidades e ONGs, bem como a revisão de compromissos, são alguns dos temas que estarão na agenda da rede para os próximos encontros.

A utilização efetiva do sistema constitui a etapa mais importante do projeto, permitindo que as pessoas interajam com ele e sejam capazes de processar as informações geradas, e que estas, por sua vez, sejam úteis, adicionando valor aos processos de planejamento estratégico, de desenvolvimento de competências e de gestão do conhecimento.

O grau de institucionalização do sistema nas instituições depende do envolvimento, interação e utilização pelos dirigentes, gestores e parceiros locais, cuja adesão é voluntária.

Medidas como a construção de ambiente mais favorável a trocas informais deverão ser estimuladas para que as pessoas que utilizam o sistema tenham outros incentivos para o intercâmbio, como nas redes sociais, o que acabaria fortalecendo o próprio funcionamento da Rede de Escolas.

O desafio de incrementar o uso do sistema não pode ser dissociado das ações de fortalecimento da rede, que deve incluir mais do que a utilização de tecnologias de informação e comunicação. A modalidade rede - uma forma associativa cada vez mais em proliferação no campo social, econômico e organizacional - implica o debate sobre as ideias, propostas e objetivos das pessoas que a compõem.

O Sistema Mapa é apenas um meio para obter alguns desses objetivos e será mais efetivo se as pessoas entenderem o potencial e seu alcance. Por esse motivo, está em fase de criação uma ferramenta amigável para trocas informais entre os membros da rede, que terá link no próprio Sistema Mapa, a fim de propiciar aos seus membros oportunidades de diálogo aberto, colaboração e parcerias.

O trabalho de difusão e mobilização de gestores e dirigentes deve ser contínuo, pois a gestão da informação e sua transformação em conhecimento explícito dependem fundamentalmente do relacionamento que as pessoas que compõem a rede forem capazes de construir. Como o sistema é novo, é necessário realizar avaliações periódicas sobre a adesão das Escolas e confiabilidade dos dados inseridos, com o intuito de desenhar outras estratégias de atração, interação e participação dos atores envolvidos.

As informações produzidas pelo Sistema Mapa podem auxiliar o processo decisório em função de sua capacidade de reduzir o grau de incerteza em relação ao que vem sendo feito na área de desenvolvimento de pessoas, auxiliando os gestores e dirigentes a planejarem e monitorarem planos de capacitação, utilizando de forma eficiente a oferta existente na rede.

As informações produzidas pelo Sistema Mapa poderão subsidiar iniciativas para aprimorar e otimizar a oferta de capacitação das Escolas da rede, ao dimensionar as oportunidades que as escolas de governo podem oferecer num futuro próximo, no caso de haver competências necessárias que não vêm sendo desenvolvidas. Permitem a comparação de conteúdos e sua classificação em áreas de conhecimento, a identificação de tendências de capacitação, temas emergentes, lacunas e potenciais para o desenvolvimento de competências. Poderão ainda facilitar a disseminação de informações e geração de conhecimento sobre cursos, 
avaliação, público-alvo, colaboradores, conteúdos, competências, capacidade instalada, além da possibilidade de intercâmbio de pesquisas, publicações, indicadores de gestão das escolas, concursos realizados etc.

O Sistema Mapa cria condições para melhor gestão do conhecimento à medida que converte informações em conhecimento. No entanto, este somente poderá ser gerado e ter utilidade à tomada de decisões quando o sistema for efetivamente incorporado e utilizado como ferramenta de gestão pelos integrantes da rede.

(Artigo recebido em outubro de 2010. Versão final em novembro de 2010).

\section{Notas}

1 Esse artigo é uma versão revista e atualizada do texto apresentado no XIV Congreso Internacional del CLAD sobre la Reforma del Estado y de la Administración Pública. Salvador, Bahia, Brasil. 27 - 30 de outubro de 2009. Painel Gestão do Conhecimento para a Melhoria e Transparência da Gestão Pública. As opiniões expressas neste artigo são de responsabilidade dos seus autores.

2 O Projeto, cuja execução iniciou em abril de 2008, contou com recursos do Programa de Fomento a Projetos de Desenvolvimento e Gestão de Pessoas, do Ministério do Planejamento, Orçamento e Gestão (MP) e da Escola Nacional de Administração Pública (ENAP).

3 Existem divergências entre as estimativas feitas pelo Instituto de Pesquisa Econômica Aplicada - Ipea - (tabela 1) e os números disponibilizados pela Secretaria de Recursos Humanos do Ministério do Planejamento, Orçamento e Gestão (SRH-MP). Entretanto, para os objetivos deste texto, as estimativas apresentadas são suficientes para ilustrar a distribuição dos servidores.

4 O Sistema Mapa está disponível aos gestores públicos dos três níveis de governo e às instituições participantes da Rede de Escolas no seguinte endereço: http:/ / mapa.enap.gov.br.

5 A ferramenta Moodle (Modular Object-Oriented Dynamic Learning Environment) foi adaptada para a primeira fase do projeto e transformou-se num repositório de informações das instituições da Rede de Escolas, que foram transferidas para o Sistema Mapa e organizadas segundo as áreas do vocabulário controlado.

6 A opção por um formulário de campos não obrigatórios fez parte da estratégia de facilitar e incentivar o preenchimento pelas escolas.

7 Os descritores estão organizados em cinco níveis de subordinação: cada descritor de nível 5 está subordinado a um ou mais descritores de nível 4 que, por sua vez, estão subordinados ao nível três e assim por diante. O nível mais alto é o nível 1, que também é o mais genérico. Quanto mais descemos na hierarquia, mais o descritor se torna específico.

8 O sistema permite que cada escola informe suas capacitações a partir do catálogo de oferta de cursos, e também insira informações sobre quantas vezes determinado curso ocorreu dentro da instituição, identificando o número de pessoas capacitadas em suas diversas ocorrências. Cada um dos participantes pode ser identificado de forma unívoca, já que existe um cadastro único, que utiliza o CPF como chave de controle.

9 A partir de convênio com a Receita Federal foi possível, a partir da utilização do CPF, fazer uma ligação entre as informações de nome, filiação e data de nascimento dos colaboradores ou 
participantes de determinado curso. Essas três informações não podem ser alteradas pelas escolas, $\mathrm{O}$ que traz estabilidade ao banco de dados.

10 É importante notar que as análises feitas neste trabalho são provisórias, pois somente 81 das 170 instituições inseriram dados e, em muitos casos, não houve atualização para 2010.

\section{Referências bibliográficas}

BEAL, Adriana. Gestão estratégica da informação: como transformar a informação e a tecnologia da informação em fatores de crescimento e de alto desempenho nas organizações. São Paulo: Atlas, 2004.

Brasil. Decreto n ${ }^{\circ}$ 5.707, de 23 de fevereiro de 2006. Institui a Política e as Diretrizes para o Desenvolvimento de Pessoal da administração pública federal direta, autárquica e fundacional, e regulamenta dispositivos da Lei no 8.112, de 11 de dezembro de 1990. Brasil. Secretaria de Assuntos Estratégicos da Presidência da República. Instituto de Pesquisa Econômica Aplicada (Ipea). Emprego público no Brasil: comparação internacional e evolução recente. Comunicado da Presidência do IPE A, n. 19, Brasília, 2009. Documento disponível em: http://www.ipea.gov.br/sites/000/2/comunicado_presidencia/ 09_03_30_ComunicaPresi_EmpPublico_v19.pdf. Acesso em outubro de 2010.

Brasil. Ministério do Planejamento, Orçamento e Gestão. Secretaria de Recursos Humanos. Boletim Estatístico de Pessoal,n. 171, Brasília, 2010. Documento disponível em: http:/ /www.servidor.gov.br/publicacao/boletim_estatistico/bol_estatistico_10/ Bol171_jul2010.pdf. Acesso em outubro de 2010.

Kobashi, Nair. Vocabulário controlado: estrutura e utilização. Texto preparado para VI Encontro da Rede Nacional de Escolas de Governo. Dezembro de 2008, Brasília, 2008. (Mimeo)

Martinho, Cássio. O projeto das redes. Revista Aminoácidos, Brasília, AED, 2002.

Olson (1971), Mancur. The logic of collective action: public goods and the theory of groups. Cambridge: Havard University, 1995 (16 impressão). 


\section{Resumo-Resumen-Abstract}

Mapeamento da oferta de capacitação nas escolas de governo no Brasil: gestão da informação para fortalecimento da gestão pública

Elisabete Ferrarezi e João Alberto Tomacheski

Esse texto tem por objetivo apresentar os resultados parciais do projeto "Mapeamento da Oferta de Capacitação nas Escolas de Governo" e debater as possibilidades que se abrem para a gestão do conhecimento e para o gerenciamento das informações estratégicas visando à tomada de decisões e a otimização dos recursos disponíveis para a capacitação.

O projeto mapeamento tem por objetivo coletar dados da oferta existente de capacitação em escolas de governo brasileiras, em nível municipal, estadual e federal. Foi concebido em três fases: coleta das informações cadastrais e sobre a disponibilidade de cursos; construção do vocabulário controlado e classificação dos cursos; e transposição dessas informações para um sistema de informações com interface web: o Sistema Mapa.

O Sistema Mapa, se efetivamente incorporado e utilizado, poderá constituir um sistema de informação que auxilie os gestores e dirigentes a planejar e realizar planos de capacitação, utilizando de forma eficiente a oferta existente nas escolas de governo. Além disso, poderá contribuir para melhor coordenação das atividades de capacitação, incentivo à complementaridade, redução de duplicidades e incentivo à ampliação da comunicação entre as instituições da Rede.

Palavras-chave: Mapeamento da oferta de capacitação - Rede Nacional de Escolas de Governo Sistema Mapa - formação de servidores públicos.

\section{Resumen: Mapeo de la oferta de capacitación en las escuelas de gobierno en Brasil: gestión de la información para fortalecimiento de la gestión pública \\ Elisabete Ferrarezi y João Alberto Tomacheski}

Este texto tiene por objeto presentar los resultados parciales del proyecto "Mapeo de la Oferta de Capacitación en las Escuelas de Gobierno" y debatir las posibilidades abiertas para la gestión del conocimiento y de las informaciones estratégicas, mirando hacia la toma de decisiones y optimización de los recursos disponibles para la capacitación.

El proyecto de mapeo tiene la finalidad de recolectar datos de la oferta de capacitación existente en escuelas de gobierno brasileñas a nível municipal, estatal y federal. Ha sido concebido en tres fases: recolecta de las informaciones catastrales y sobre la disponibilidad de cursos, construcción del vocabulario controlado y clasificación de los cursos, y traslado de estas informaciones para un sistema de informaciones con interfaz Web: el Sistema Mapa.

El Sistema Mapa, si efectivamente incorporado y utilizado, podrá constituir un sistema de información que auxilie a los gestores y dirigentes en la planificación y realización de proyectos de capacitación, utilizando eficientemente la oferta efectiva en las escuelas de gobierno. Además, podrá contribuir para mejor coordinación de las actividades de capacitación, fomento a la complementariedad, reducción de duplicidades y incentivo a la ampliación de la comunicación entre las instituciones de la Red de Escuelas.

Palabras clave: Mapeo de la oferta de capacitácion - Red Nacional de Escuelas de GobiernoSistema Mapa - la formación de los funcionarios públicos 


\section{Mapping of the Brazilian government schools capacitation offer: information management to strengthen public management}

Elisabete Ferrarezi and João Alberto Tomacheski

This text is aimed to present partial results to the "Mapping of the Brazilian government schools capacitation offer" and to debate the possibilities created to knowledge managing and strategic information management in an attempt to improve the decision making process and optimizing capacitation's resources available.

The mapping project's objective is to gather the existing data on capacitation offer from Brazilian government schools at the municipal, state and national levels. It was built in three phases: the gathering of information found on records and on courses offerings; the construction of a controlled vocabulary and course classification; as well as the transfer and adaptation of this information to a Web interfaced system: the Mapa System.

The Mapa system, if effectively incorporated and used, might constitute an information system that will help managers and directors to plan and make real the capacitation plans, using the existing offer from government schools in an efficient manner. Besides, the system will contribute to better capacitation activities coordination, encouraging complementing actions, reduction of ambiguities and incentive to communication widening between the institutions participating on the Government Schools Network.

Keywords: Mapping the capacitation offer - National Network of Schools of Government Mapa System - training of public servants

\section{Elisabete Ferrarezi}

Doutora em Sociologia pela Universidade de Brasília (UnB), mestre em Administração Pública pela Fundação Getulio Vargas (FGV/SP). Pertence à carreira do governo federal de Especialista em Políticas Públicas e Gestão Governamental desde 1996. É atualmente Coordenadora-geral de Pesquisa da Escola Nacional de Administração Pública (ENAP). Contato: elisabete.ferrarezi@enap.gov.br

João Alberto Tomacheski

Doutor em Sociologia pela Universidade de Brasília (UnB) e mestre em Ciência Política pela Universidade Federal do Rio Grande do Sul (UFRGS). Pertence à carreira de Especialista em Políticas Públicas e Gestão Governamental desde 2002. Atualmente trabalha na equipe de Pesquisa da ENAP, gerenciando o Sistema Mapa. Contato: joao.tomacheski@enap.gov.br 
